EESTI NSV TEADUSTE AKADEEMIA TOIMETISED. XIII KOIDE FCOSIKA-MATEMAATIKA- JA TEHNIKATEADUSTE SEERIA. 1964, NR. 4.

ИЗВЕСТИЯ АКАДЕМИИ НАУК ЭСТОНСКОН ССР. ТОМ ХІІГ СЕРИЯ ФИЗИКО-МАТЕМАТИЧЕСКИХ И ТЕХНИЧЕСКИХ НАУК. 1964, № 4

\title{
АДСОРБИРУЕМОСТЬ НЕКОТОРЫХ УГЛЕВОДОРОДОВ ПРИ ХРОМАТОГРАФИРОВАНИИ НА СИЛИКАГЕЛЕ
}

\author{
О. КИРРЕТ, \\ член-корреспондент АН ЭССР \\ О. ЭизЕН, \\ кандидат технических наук \\ Л. КУДРЯВЦЕВА, С. РАНГ, \\ кандидаты химических наук
}

При исследовании химического состава различных фракций нефтей и других углеводородных смесей часто применяется жидкостно-адсорбционная хроматография на силикагеле. Настоящая работа посвящена вопросам поведения некоторых углеводородов в условиях адсорбционного хроматографического анализа, которые до сих пор не нашли в. литературе достаточного освещения.

Анализ исходных смесей, а также полученных при хроматографировании на силикагеле фракций осуществлялся в настоящей работе при помощи газо-жидкостной хроматографии. Этот метод позволяет более точно, по сравнению со старыми методами проследить распределение и разделение индивидуальных соединений при хроматографировании: на: силикагеле.

\section{Методика}

Для разделения применялся силикагель марки АCM и КСМ с размером зерен, $100-200$ меш. Во избежание изомеризации олефиновых углеводородов в ряде опытов использовался предварительно обработанный: соляной кислотой и перекисью водорода силикагель.

Силикагель высушивался 6 ч при температуре $60^{\circ} \mathrm{C}$ и не менее 6 . п при температуре $150^{\circ}$. Конструкция применяемых колонок опи+ сана в [1].

Исследуемая смесь подавалась в колонку предварительно охлажденной до $0^{\circ}$. Температура воды в охладительной муфте колонки была $5^{\circ}$. После поглощения пробы силикагелем добавлялся вытеснитель - этанол. Исследуемая смесь (5-7 2) отбиралась из колонки в виде $10-15$ фракций. Состав фракций определялся газохроматографнчески на приборе УX-1.

Ниже приводится характеристика колонки, использованной для газо-хроматографического анализа:

Длина -3 м, внутренний диаметр - 4 мм, твердый носитель - Хромосорб. W 60-80 меш, жидкая фаза - 20\% Твина 80 , температура - $100-150^{\circ}$, газ носитель - гелий.

Первая искусственная смесь составлялась с целью исследования разделения на силикагеле $н$-парафинов, нафтенов и ароматических углеводородов с одинаковым молекулярным весом. Условия и результать 
Результаты хроматографирования смеси № $1^{\text {* }}$

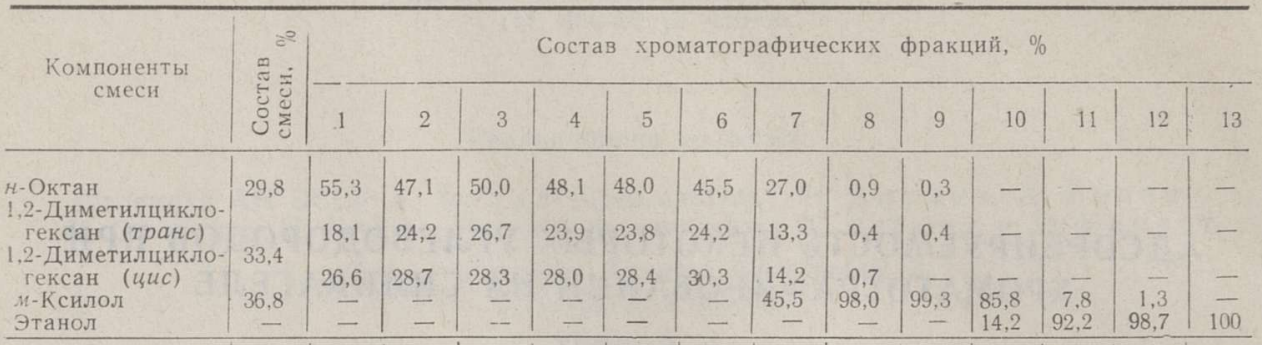

Вес фракции, г $|7,7167| 0,5987|0,7372| 0,7573|0,8029| 0,6730|0,7537| 0,8295|0,8096,0,8115| 0,9306|0,8138| 0,8470 \mid 0,9284$

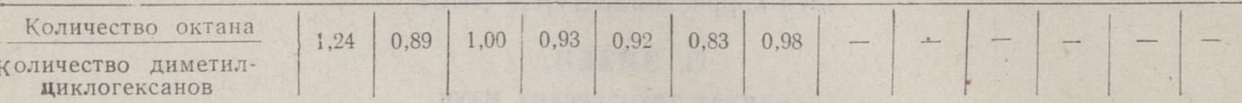

циклогексанов

* Необработанный силикагель АСМ, весовое соотношение - смесь : силикагель $1: 15$.

опыта приведены в табл. 1 и на рис. 1. Как видно из приведенных данных, разделения октана от диметилциклогексана не произошло. Во всех фракциях, за исключением первой, несколько обогащенной н-октаном, соотношение концентраций октана и диметилциклогексана осталось почти тем же, что и в начальной смеси.

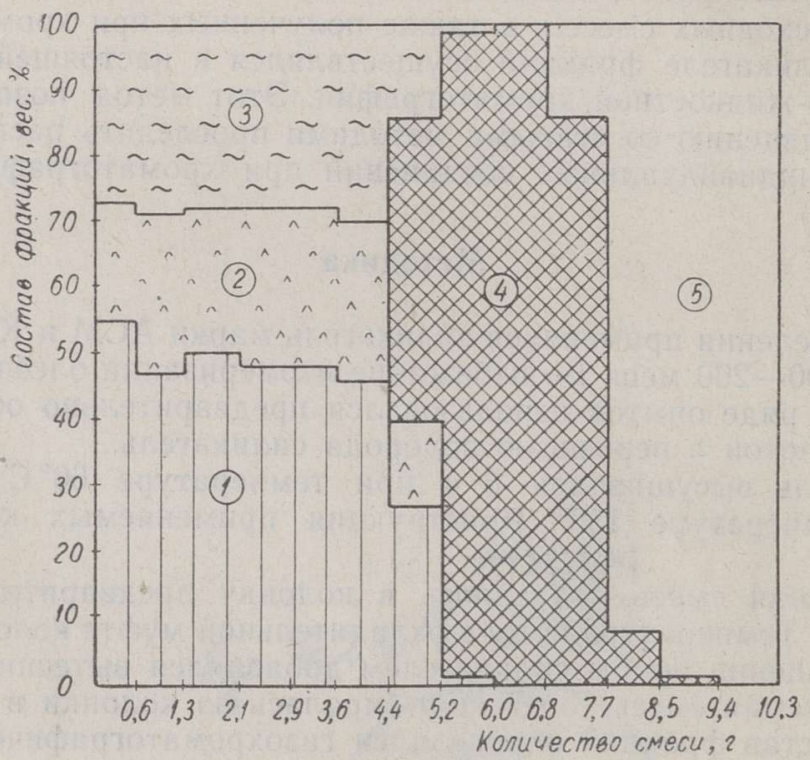

Рис. 1. Хроматограмма смесн № 1. 1 - н-октан, 2 - 1,2-диметилциклогексан (транс), 3 - 1,2-диметилциклогексан (цис), 4 - м-ксилол, 5 - этанол.

Одной из наиболее часто встречающихся проблем в групповом анализе является проблема разделения олефиновых и ароматических углеводородов. Количественная сторона указанной проблемы до настоящего времени не ясна. В связи с этим приводим данные по разделению трех смесей: 1) ароматический углеводород с 
углеводород с циклоолефином, 3) ароматический углеводород с алкенароматическим углеводородом.

Таблича 2

Результаты хроматографирования смеси № 2 *

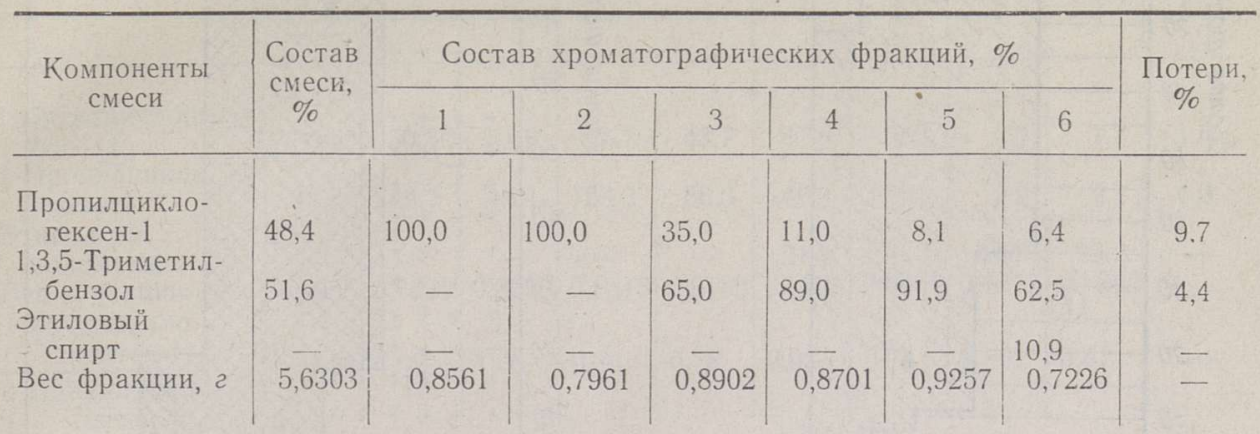

Результаты хроматографирования смеси № 3 *

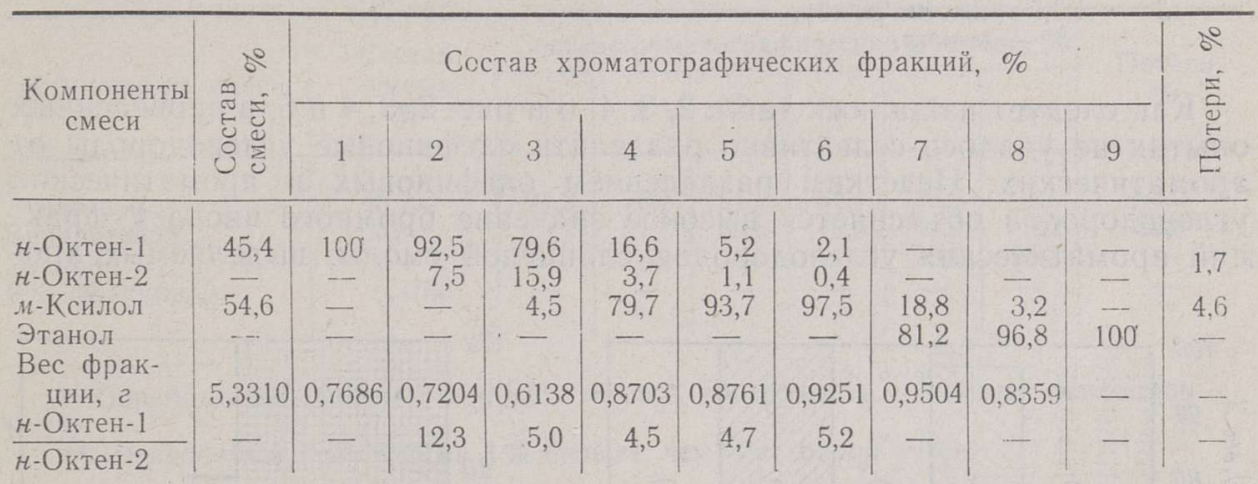

* Обработанный силикагель КСМ, весовое соотношение - смесь: силикагель -$1: 15$.

таблииа 4

Результаты хроматографирования смеси № 4 *

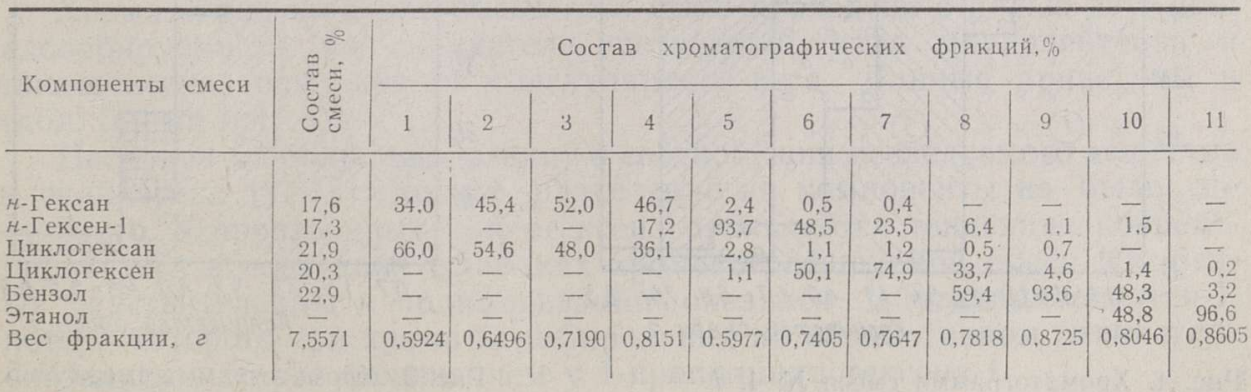

* Обработанный силикагель КСМ, весовое соотношение - смесь: силикагель -$1: 15$. 


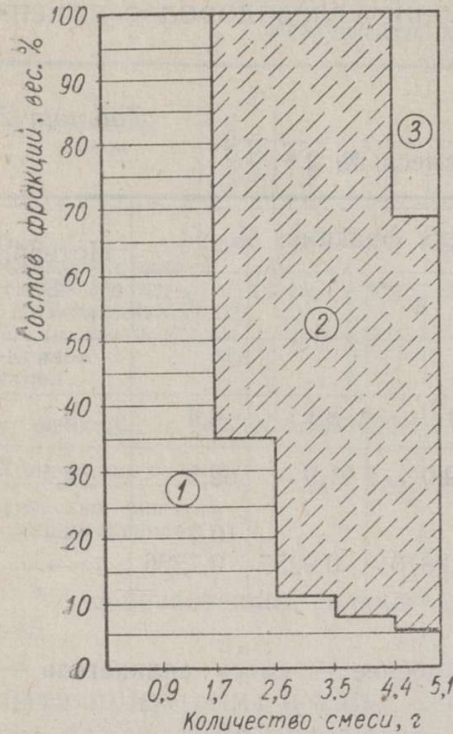

Рис. 2. Хроматограмма смеси № 2. 1 - пропилциклогексен, 2 - 1,3,5-триметилбензол, .3 - этанол.

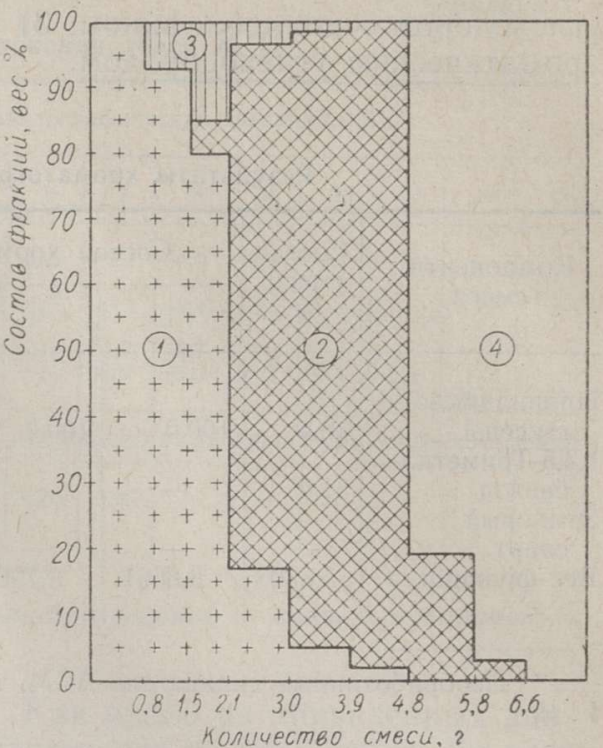

Рис. 3. Хроматограмма смеси № 3. 1 - октен-1, 2 - м-ксилол, 3 - октен-2, 4 - этанол.

Как следует из данных табл. $2,3,4,6$ и рис. $2,3,4$ и 6 , в проведенных опытах не удалось селективно разделить олефиновые углеводороды от ароматических. Нечетким разделением олефиновых и ароматических углеводородов объясняется высокое значение бромного числа у фракщий ароматических углеводородов сланцевой смолы, выделяемых хро-

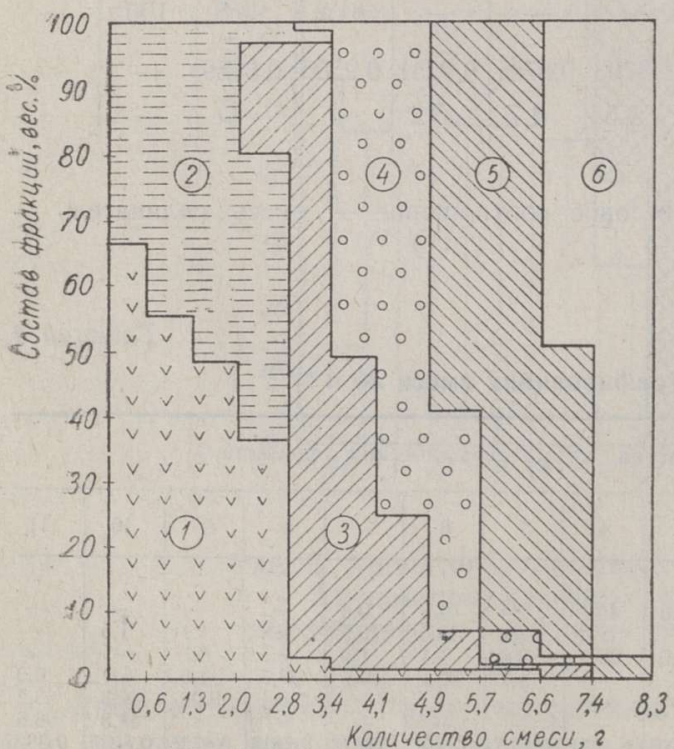

Рис. 4. Хроматограмма смеси № 4.1 циклогексан, 2 - $\mu$-гексан, 3 - $H$-гексен-1, 4 - циклогексен, 5 - бензол, 6 - этанол.

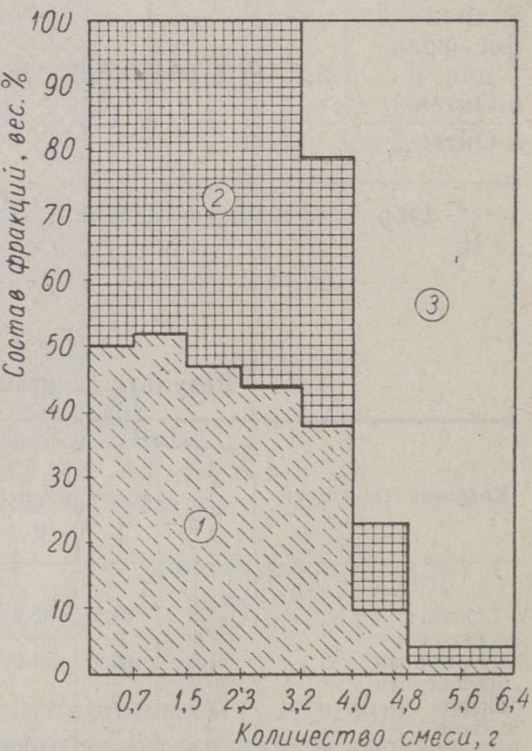

Рис. 5. Хроматограмма смеси № 5.

1 - буутициклопентен-1, 2 1-пропилциклогексен-1, 3 - этанол. 
Таблица 5

Результаты хроматографиревания смеси № 5 *

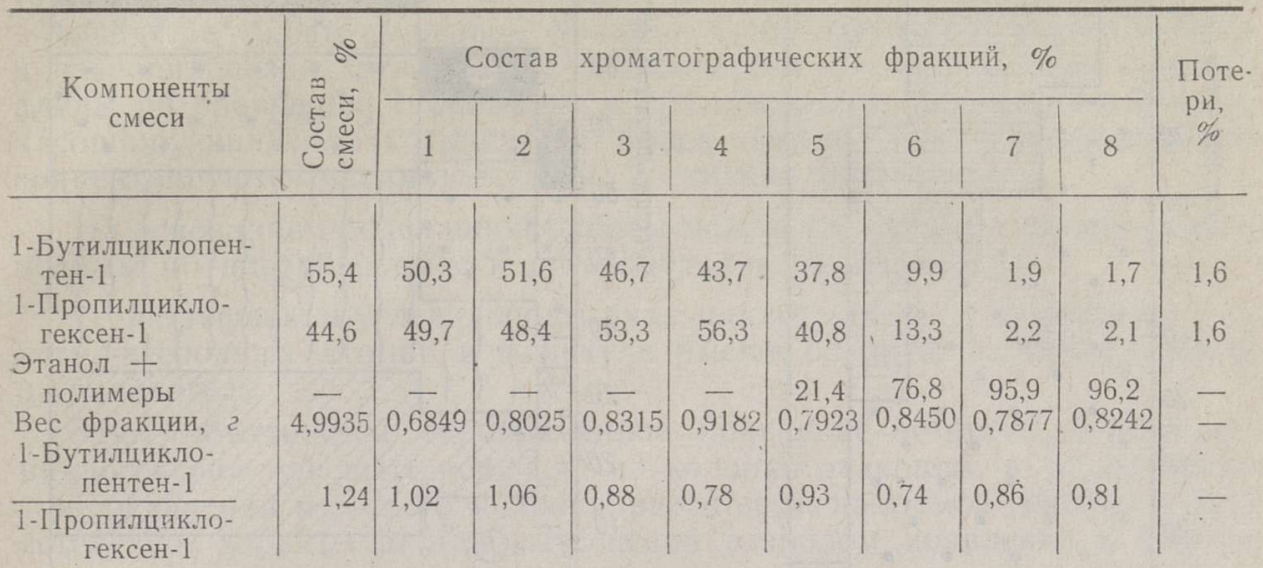
$1: 18$.

* Обработанный силикагель КСМ, весовое соотношение - смесь: силикагель --

Результаты хроматографирования смеси № 6 *

Таблица 6

\begin{tabular}{l|c|c|c|c|c|c|c|c}
\hline \multirow{2}{*}{ Компоненты смеси } & $\begin{array}{c}\text { Состав } \\
\text { смеси, } \\
\%\end{array}$ & \multicolumn{2}{|c|}{ Состав хроматографических фракцй, \% } & $\begin{array}{c}\text { Потери, } \\
\%\end{array}$ \\
\cline { 3 - 7 } & & 1 & 2 & 3 & 4 & 5 & 6 & \\
\hline Этилбензол & 48,7 & 91,3 & 78,3 & 61,5 & 51,1 & 29,6 & 1,5 & $+3,0 * *$ \\
Винилбензол & 51,3 & 8.7 & 21,7 & 38,5 & 48,9 & 42,3 & 3,2 & $-22,8$ \\
Этанол & 5,3766 & - & - & - & - & - & - & -
\end{tabular}
$1: 15$.

* Обработанный силикагель КСМ, весовое соотношение - смесь: силикагель ** Этилбензола получено на $3 \%$ больше, чем в исходной смеси.

матографированием на силикагеле $\left[{ }^{2,3}\right]$. Потери при хроматографировании, несмотря на предварительную обработку силикагеля, достаточно велики, особенно за счет полимеризации винилбензола. Предварительная обработка силикагеля соляной кислотой и перекисью. водорода не устраняет полностью изомеризации 1-олефинов в 2- и 3-изомеры (см. рис. 3).

Хроматографирование смеси № 5 было проведено с целью нзучения адсорбируемости на силикагеле соединений ряда циклопентенов и циклогексенов одинакового молекулярного веса. Данные приведены в табл. 5 и на рис.. 5 .

Несмотря на большую разницу в соотношении исследуемого вещества и силикагеля (1:18), точное разделение на компоненты не было достигнуто. У производных циклогексена проявляется тенденция концентрироваться в последних фракциях хроматографируемой смеси. Особенно чувствительным к полимеризации оказался 1-бутилциклопентен-1, потери которого при хроматографировании на обработанном силикагеле оказались в 10 раз больше, чем у 1-пропилциклогексена-1.

Смесь № 4 составлена йз парафиновых, олефнновых, циклопарафиновых, циклоолефиновых и ароматических углеводородов, молекулы 


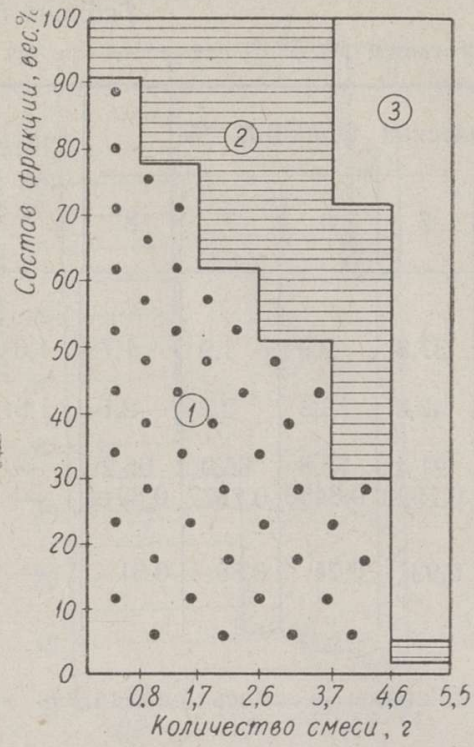

Рис. 6. Хроматограмма смесн № 6. 1 - этилбензол, 2 - ви . нилбензол, 3 - этанол.

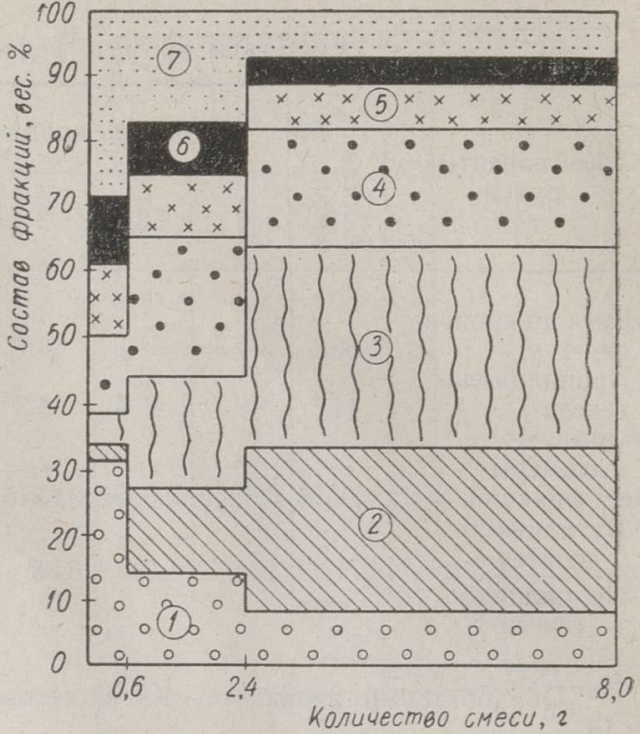

Рис. 7. Хроматограмма смеси № 7. 1 - циклогексен, 2 - бензол, 3 - толуол, 4 - этилбензол, 5 - нзопропилбензол, 6 - н-пропилбензол, 7 - н-бутилбензол.

которых состоят из одинакового числа углеродных атомов. Циклосоединения подобраны без боковой цепи, чтобы не увеличивать число влияющих на адсорбцию факторов и выяснить адсорбируемость нафтеновых, олефиновых и ароматических колец на силикагеле. Данные приведены в табл. 4 и на рис. 4.

Из этих данных следует, что полного разделения гексана и циклогексана добиться не удалось, хотя циклогексан и концентрируется в первых фракциях. Гек-

Таблиц 7 сен-1 четко отделяется от

Результаты хроматографирования смеси № 7 *

\begin{tabular}{l|r|r|r|r}
\hline \multirow{2}{*}{ Компоненты ємеси } & $\begin{array}{c}\text { Состав } \\
\text { смеси, \% }\end{array}$ & \multicolumn{2}{|c}{$\begin{array}{c}\text { Состав хромато- } \\
\text { графических } \\
\text { фракций, \% }\end{array}$} \\
\cline { 3 - 5 } & & 1 & 6 & 13 \\
\hline Циклогексен & 16,2 & 31,1 & 13,9 & 8,0 \\
Бензол & 16,7 & 2,5 & 13,1 & 25,2 \\
Толуол & 16,6 & 3,6 & 17,3 & 30,6 \\
Этилбензол & 16,8 & 12,3 & 20,7 & 18,1 \\
Изопропилбензол & 8,9 & 11,3 & 10,0 & 7,0 \\
Пропилбензол & 7,8 & 10,0 & 8,2 & 4,1 \\
н-Бутилбензол & 17,0 & 29,2 & 16,8 & 7,0 \\
& & & & \\
\hline
\end{tabular}

* Обрабстанный силикагель КСМ, весовое соотношение - смесь : силикагель - $1: 20$. циклогексана и гексана, и хуже - от циклогексена. Разделимы также бензол и циклогексен, несмотря на наличие довольно большой промежуточной фракции.

Для выяснения адсорбируемости алкилбензолов в зависимости от их строения и длины боковой цепи были проведены исследования со гмесью № 7. Результаты приведены в табл. 7 и на рис. 7. Из данных хроматографирования смеси № 7 следует, что циклогексен и ароматические углеводороды разделяются лишь частично, причем циклогексен концентрируется в первой фракции. Силь- 
нее всего адсорбируются бензол и толуол. Чем длиннее боковая цепь, тем слабее адсорбнруется соединение на поверхности силикагеля. Этим объясняется то, что в первой фракции концентрируется н-бутилбензол и $н$-пропилбензол. Этилбензол, обладающий боковой цепью средней длины по сравнению с бензолом и бутилбензолом, и изопропилбензол, адсорбируюшийся на силикагеле более сильно, чем н-пропилбензол, концентрируются преимущественно в средних фракциях.

На основании проделанной работы можно сделать следующие общие выводы об адсорбируемости углеводородов на снликагеле:

1. Парафины и углеводороды ряда циклогексана с одинаковым числом углеродных атомов в молекуле имеют близкую адсорбируемость на силикагеле.

Этим объясняется одновременное появление н-октана и диметилциклогексана при вытеснении их из колонки этанолом, в то же время для соединений меньшего молекулярного веса, например гексана и циклогексана, характерно при вытеснении этанолом появление в гервую очередь циклогексана.

2. Углеводороды циклопентенового ряда располагаются по адсорбируемости между н-олефинами и соединениями циклогексенового ряда. Полного разделения циклогексенов и циклопентенов хроматографированием на силикагеле достигнуть не удалось.

3. н-Олефиновые углеводороды можно полностью отделить от ароматических углеводородов, в то время как изо- и циклоолефиновые углеводороды неполностью отделяются от ароматических.

4. Адсорбируемость ароматических углеводородов с алкильной труппой одинакового строения уменьшается с ростом длины боковой цепи. Так, по сравнению с бензольным кольцом парафиновые боковые цепи проявляют пропорционально каждой группе $\mathrm{CH}_{2}$ отрицательную адсорбируемость.

Отталкивающая сила изегрупп в боковых цепях менее сильна, чем в случае нормальных боковых цепей. Этим объясняется большая адсорбируемость изоалкилбензолов по сравнению с нормальными алкилбензолами. Отталкивающая сила боковой цепи может быть в известной мере ослаблена введением в боковую цепь двойной связи. Так, напркмер, винилбензол адсорбируется значительно сильнее, чем этилбензол.

Низкой адсорбируемостью различных по строению боковой цепи алкилбензолов объясняется малая селективность их разделения с циклогексенами. Циклогексен и бутилбензол не разделяются (табл. 7).

5. В качестве общего правила можно привести уменьшение адсорбируемости соединения с ростом числа групп - $\mathrm{CH}_{2}-$. Адсорб́ируемость растет с ростом числа двойных связей. Исследованные в настояшей работе углеводороды по степени увеличения адсорбируемости можно расположить в следующий ряд: н-октан, диметилциклогексан, циклогексан, н-гексен-1, бутилциклопентен-1, пропилциклогексен-1, циклогексен, бутилбензол, этилбензол, толуол, 'винилбензол, бензол. 
1. Топчиев В. В., Исхаков а Э. Х., М усаев И. А., Г альперн, Г. Д., Химия и технология топлива; № $11,26(1957)$.

2. Р анг С. А., Об индивидуальном состәве эстонского сланцевого бензина, Автореферат диссертации. Таллин, 1961.

3. Э й з ен О. Г., О химическом состазе средних фракций генераторной смолы эстонских горючих сланцев, Горючне сланцы. Химия и технология, вып. 4, Таллин, 1961.

Ннститут химии

Академии наук Эстонской ССР
Поступила в редакцию

30 IV 1964

\title{
MÕNINGAID ANDMEID SÜSIVESINIKE ERALDATAVUSE KOHTA SILIKAGEELIL KROMATOGRAFEERIMISE PUHUL
}

\author{
O. Kirret, \\ ENSV TA korrespondentliige
}

\author{
o. Eisen, \\ tehnikateaduste kandidaat \\ L. Kudrjavtseva, S. Rang, \\ keemiateaduste kandidaadid
}

\section{Resümee}

Iöös käsitletakse raskesti eraldatavate süsivesinike segude lahutamise võimalusi silikageeli eri markidel ja erinevail kromatografeerimise tingimustel. Uuriti n-parafiinide ja tsükloparafiinide, n-olefiinide ja tsükloolefiinide, tsükloolefiinide ja aromaatsete süsivesinike ning erineva külgahela pikkusega aromaatsete süsivesinike adsorptsiooni. Adsorptsioon-kromatograafiliste fraktsioonide keemilise koosseisu määramine toimus gaasikromatograafiliselt. See meetod võimaldas saada täpsustatud kvantitatiivseid andmeid individuaalsete süsivesinike eraldatavuse kohta.
Eesti NSV Teaduste Akadeemia
Keemia Instituut
Saabus toimetusse
30. IV 1964

\section{ADSORPTIVITY OF SOME HYDROCARBONS IN THE PROCESS OF LIQUID-SOLID CHROMATOGRAPHY ON SILICAGEL}

\author{
O. Kirret, O. Eisen, L. Kudryavtseva, S. Rang
}

\section{Summary}

The possibilities of separating not easily divisible mixtures of hydrocarbons on various marks of silikagel and under various conditions of adsorption chromatography have been studied in this work. The divisibility of various systems of hydrocarbons such as n-paraffins-cycloparaffins, n-olefins-cycloolefins, cycloolefins-aromatic hydrocarbons and aromatic hydrocarbonswith various lengths and structure of branched chain has been investigated. The composition of chromatographic fractions was determined by gas-liquid chromatography. This enabled to get a thorough survey of separating the above-mentioned hydrocarbons with the help of adsorption chromatography. The laws of adsorption of these hydrocarbons on silicagel have been pointed out in the paper. 